Supporting information for

\title{
Effect of Cationic Charge Density on Transcytosis of Polyethylenimine
}

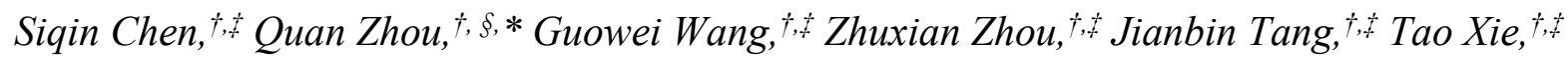
and Youqing Shen ${ }^{\dagger, t}, *$

$\dagger$ Center for Bionanoengineering, Key Laboratory of Biomass Chemical Engineering of the Ministry of Education, College of Chemical and Biological Engineering, Zhejiang University, Hangzhou 310027, China.

$\S$ Department of Cell Biology, Zhejiang University School of Medicine, Zhejiang University, Hangzhou, 310058, China.

$\$$ Hangzhou Global Scientific and Technological Innovation Center, Hangzhou 311215, China.

*Corresponding author: quanzhou91@zju.edu.cn, shenyq@zju.edu.cn

\section{This file includes:}

Figure S1. ${ }^{1} \mathrm{H}-\mathrm{NMR}$ spectra of PEI and AcPEIs.

Table S1. The acetylation degrees of primary and secondary amines in AcPEIs determined by the ${ }^{1} \mathrm{H}-\mathrm{NMR}$ spectra.

Figure S2. The raw data of AcPEIs' zeta potentials.

Figure S3. Quantify the proportion of Cy5-stained cells in ${ }^{\mathrm{Cy}} \mathrm{AcPEIs}$ treated MTSs.

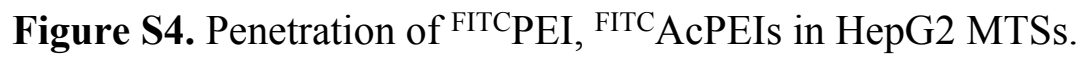

Figure S5. Trans-endothelial transport of ${ }^{\mathrm{Cy} 5}$ AcPEIs across the HUVEC cells.

Figure S6. Colocalization of ${ }^{\mathrm{Cy} 5} \mathrm{AcPEI}_{24 \%}$ (red) with lysosomes (green) observed by CLSM.

Figure S7. Colocalization of ${ }^{\mathrm{Cy} 5} \mathrm{AcPEI}_{87 \%}$ (red) with lysosomes (green) observed by CLSM.

Figure S8. Cytotoxicity of ${ }^{\mathrm{Cy} 5} \mathrm{PEI}$ or ${ }^{\mathrm{Cy} 5} \mathrm{AcPEI}_{24 \%}$ (red) against HepG2 cells determined by propidium iodide staining (green).

Figure S9. Imaging the budding of extracellular vesicles (EVs) in ${ }^{\mathrm{Cy} 5} \mathrm{PEI}$ treated HepG2 cells. 


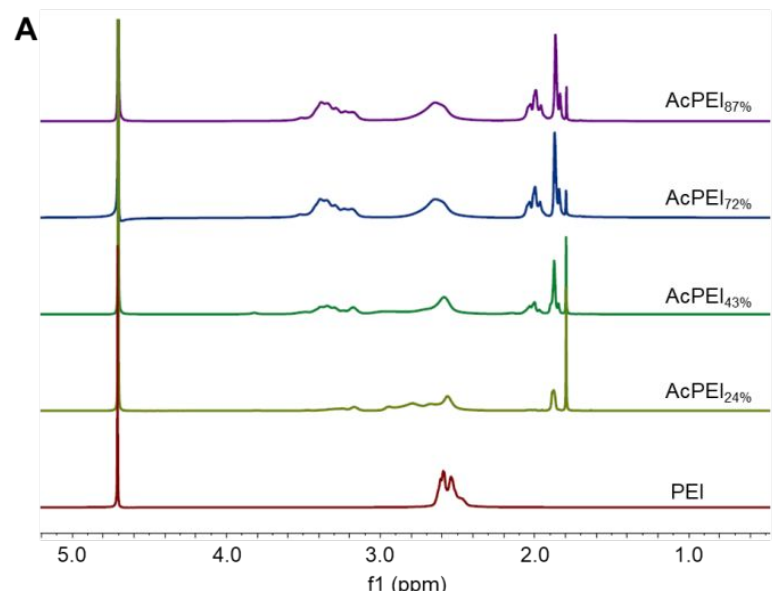

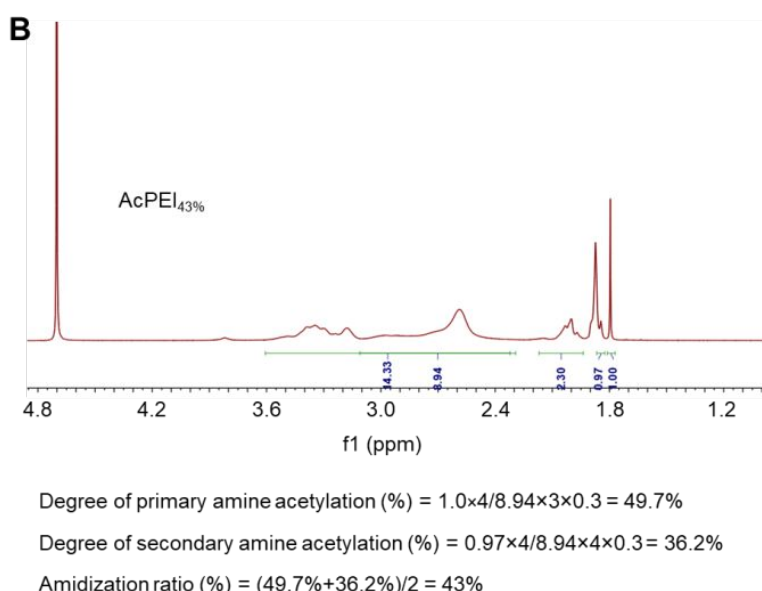

Figure S1. ${ }^{1}$ H-NMR spectra of PEI and AcPEIs. (A) ${ }^{1} \mathrm{H}-\mathrm{NMR}$ spectra of PEI and AcPEIs. (B) Percentage of acetylation determined by ${ }^{1} \mathrm{H}-\mathrm{NMR}$. The $\mathrm{AcPEI}_{43 \%}$ was used as an example here, the acetylation degree of primary and secondary amine was determined by peak integration using the following formula: 1) Degree of primary amine acetylation $(\%)=\frac{4 \mathrm{M}^{\prime}}{\mathrm{E}_{\mathrm{bb}} \times 3 \mathrm{~N}^{\prime}}$ $\times 100 \%$; 2) Degree of secondary amine acetylation $(\%)=\frac{4 \mathrm{M}^{\prime \prime}}{\mathrm{E}_{\mathrm{bb}} \times 3 \mathrm{~N}^{\prime \prime}} \times 100 \%$. Where $\mathrm{M}^{\prime}$ represents the integration of the peaks of $\delta 1.7-1.75\left(\mathrm{R}-\mathrm{NH}-\mathrm{COCH}_{3}\right.$, acetylated primary amines), $\mathrm{M}^{\prime \prime}$ is the integration of the peaks of $\delta 1.8-1.85\left(\mathrm{R}_{2}-\mathrm{NCOCH}_{3}\right.$, acetylated secondary amines), and $\mathrm{E}_{\mathrm{bb}}$ is the integration of peaks of $\delta$ 2.3-2.8 (ethylene backbone). $\mathrm{N}^{\prime}$ and $\mathrm{N}^{\prime \prime}$ are the mole fractions of primary and secondary amines of PEI, which are 0.3 and 0.4 , respectively. Other acetylation degrees of primary and secondary amines in AcPEIs were calculated at a similar method, and the results are shown in Table S1.

Table S1. The acetylation degrees of primary and secondary amines in AcPEIs determined by the ${ }^{1} \mathrm{H}-\mathrm{NMR}$ spectra.

\begin{tabular}{ccccccc}
\hline & \multirow{2}{*}{$\begin{array}{c}\text { Amidization } \\
\text { ratio }\end{array}$} & $\begin{array}{c}\mathrm{NH}_{2} \\
\text { acetylated }^{\mathrm{a}}\end{array}$ & $\begin{array}{c}\text {-NH } \\
\text { acetylated }\end{array}$ & & \multicolumn{2}{c}{ Mole fraction of amines $^{\mathrm{b}}$} \\
\cline { 5 - 7 }${ }^{\mathrm{Cy} 5} \mathrm{PEI}$ & $\mathbf{0}$ & - & - & $30 \%$ & $40 \%$ & $30 \%$ \\
$\mathrm{AcPEI}_{24 \%}$ & $\mathbf{2 4 \%}$ & $32.6 \%$ & $18.1 \%$ & $20.2 \%$ & $42.6 \%$ & $37.2 \%$ \\
$\mathrm{AcPEI}_{43 \%}$ & $\mathbf{4 3 \%}$ & $49.7 \%$ & $36.2 \%$ & $15.1 \%$ & $40.4 \%$ & $44.5 \%$ \\
$\mathrm{AcPEI}_{72 \%}$ & $\mathbf{7 2 \%}$ & $77.7 \%$ & $67.0 \%$ & $6.7 \%$ & $36.5 \%$ & $56.8 \%$ \\
AcPEI $_{87 \%}$ & $\mathbf{8 7 \%}$ & $96.2 \%$ & $80.6 \%$ & $1.1 \%$ & $36.6 \%$ & $62.3 \%$ \\
\hline
\end{tabular}

\footnotetext{
${ }^{\text {a }}$ Percentage of acetylation determined from ${ }^{1} \mathrm{H}-\mathrm{NMR}$ spectra

${ }^{\mathrm{b}}$ Mole fractions calculated from the percentage of acetylation
} 

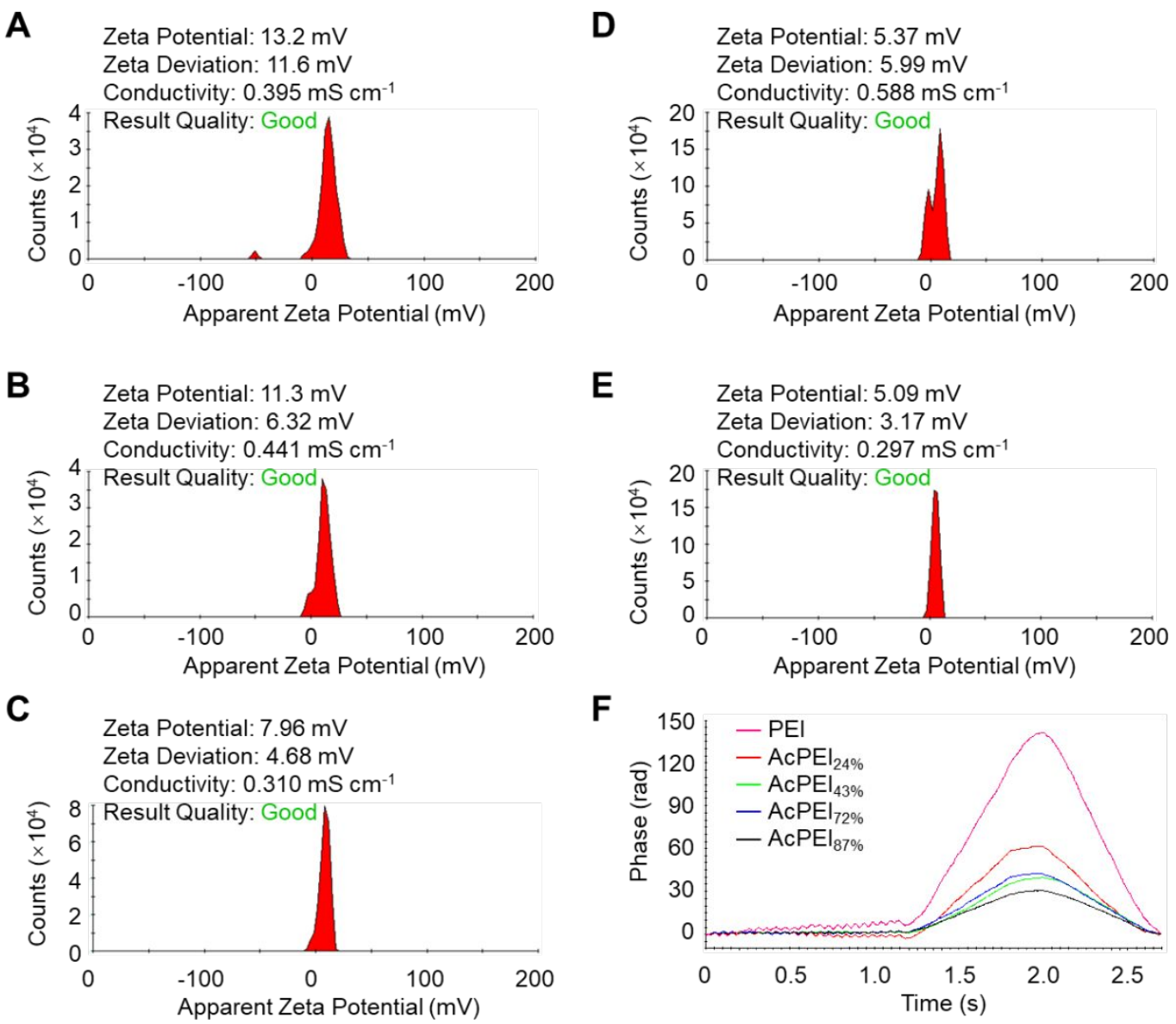

Figure S2. The raw data of AcPEIs' zeta potentials. (A-E) Representative zeta potential distributions of PEI and AcPEIs; (F) Phase plots of the PEI and AcPEIs.
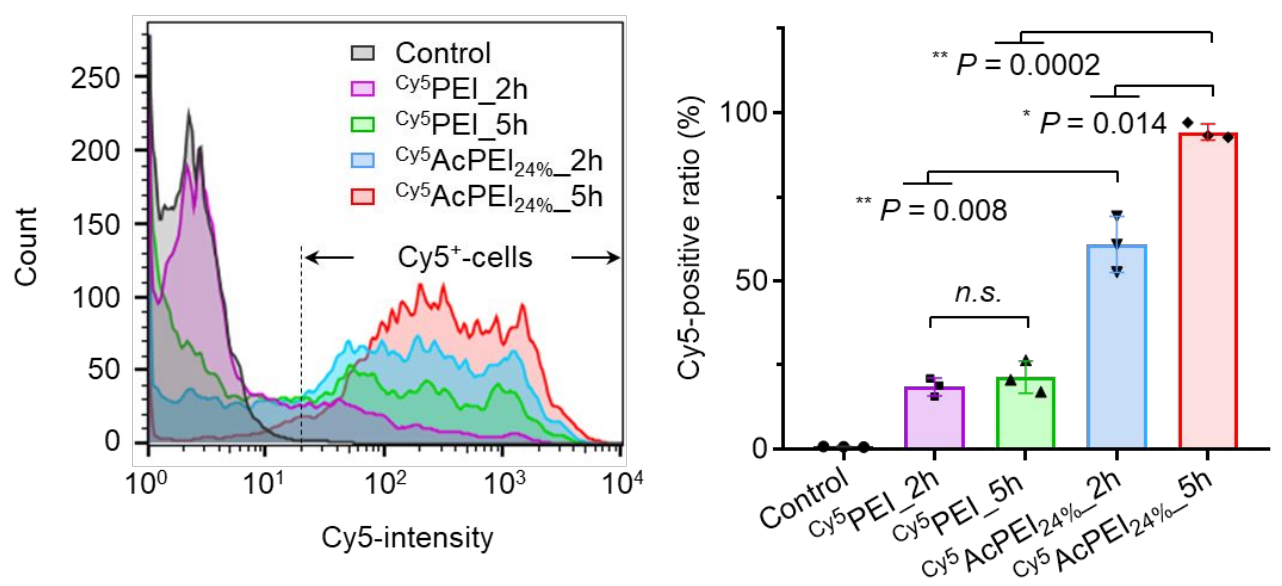

Figure S3. Quantify the proportion of Cy5-stained cells in ${ }^{\mathrm{Cy}}{ }^{\mathbf{A}} \mathrm{AcPEIs}$ treated MTSs. HepG2 MTSs are separately incubated with ${ }^{\mathrm{Cy}}{ }^{5} \mathrm{PEI}$ and ${ }^{\mathrm{Cy}} \mathrm{AcPEI}_{24 \%}(\mathrm{Cy} 5$-equiv dose $0.5 \mu \mathrm{g}$ $\mathrm{mL}^{-1}$ ) for $2 \mathrm{~h}$ or $5 \mathrm{~h}$, then digested with trypsin and collagenase $\mathrm{P}$, the obtained cell suspensions are washed twice with PBS for flow-cytometry analysis. Data are mean \pm s.d. $(n=3)$; Significances are determined by one-way ANOVA with Tukey's correction and 95\% confidence intervals; $P$ values are indicated above the plot; $n . s$., no significant difference. 
A

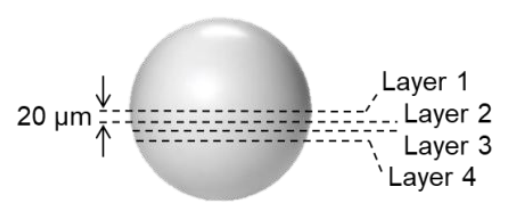

B

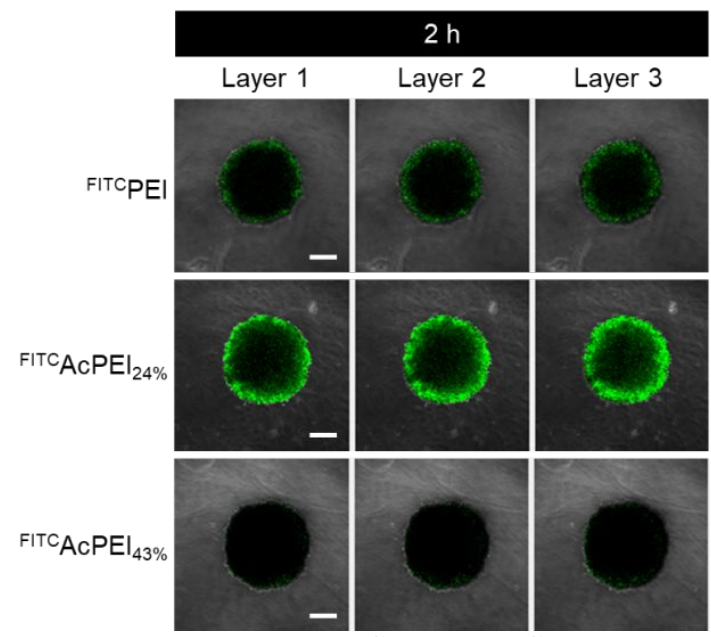

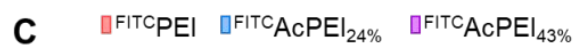
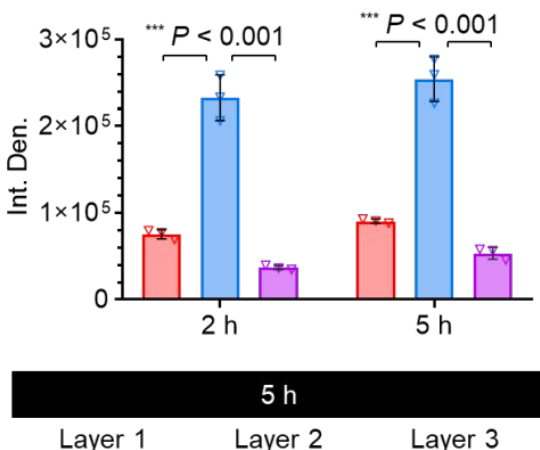
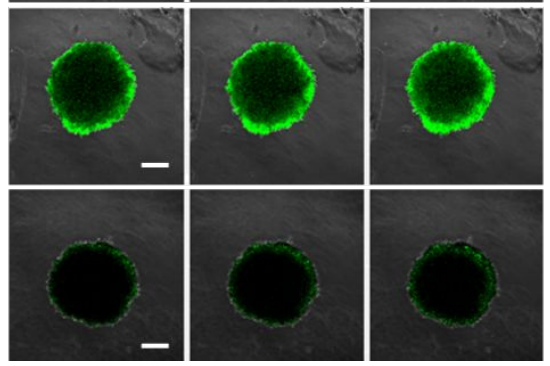

Figure S4. Penetration of FITCPEI, FITC AcPEIs in HepG2 MTSs. (A) Schematic diagram of Z-stack tomoscan at $20 \mu \mathrm{m}$ intervals in MTS. (B) Representative CLSM images of the middle

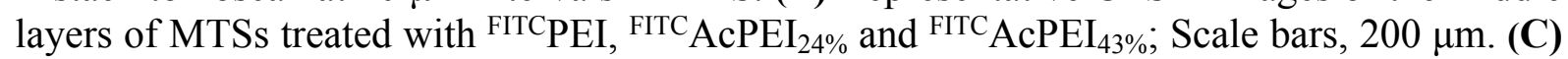
The integrated optical density (Int. Den.) of the FITC fluorescence in $(B)$ are quantitated by ImageJ software; Data are shown as mean \pm s.d., $n=3$; Significances are determined by oneway ANOVA with Tukey's correction and 95\% confidence intervals; $P$ values are indicated above the plot.

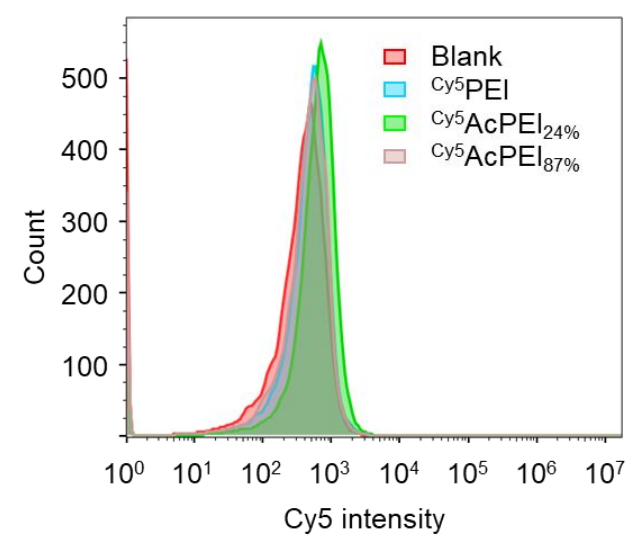

Figure S5. Trans-endothelial transport of ${ }^{C y 5}$ AcPEIs across the HUVEC cells. Endothelial HUVEC cells are seeded onto transwell polycarbonate cell culture inserts (24-well) at a density of $5 \times 10^{5}$ cells per well, BxPC3 cells are seeded in 24-wells for flow cytometry analysis. After the TEER value is above $30 \Omega \cdot \mathrm{cm}^{2}$, the medium in the apical compartment is replaced with 0.2 $\mathrm{mL}$ fresh medium containing ${ }^{C y} 5$ AcPEIs (Cy5-equiv $0.5 \mu \mathrm{g} \mathrm{mL} \mathrm{m}^{-1}$ ) and incubated for $6 \mathrm{~h}$. Afterwards, BxPC3 cells are washed twice with PBS and collected in $0.5 \mathrm{~mL}$ PBS for flow cytometry analysis. 

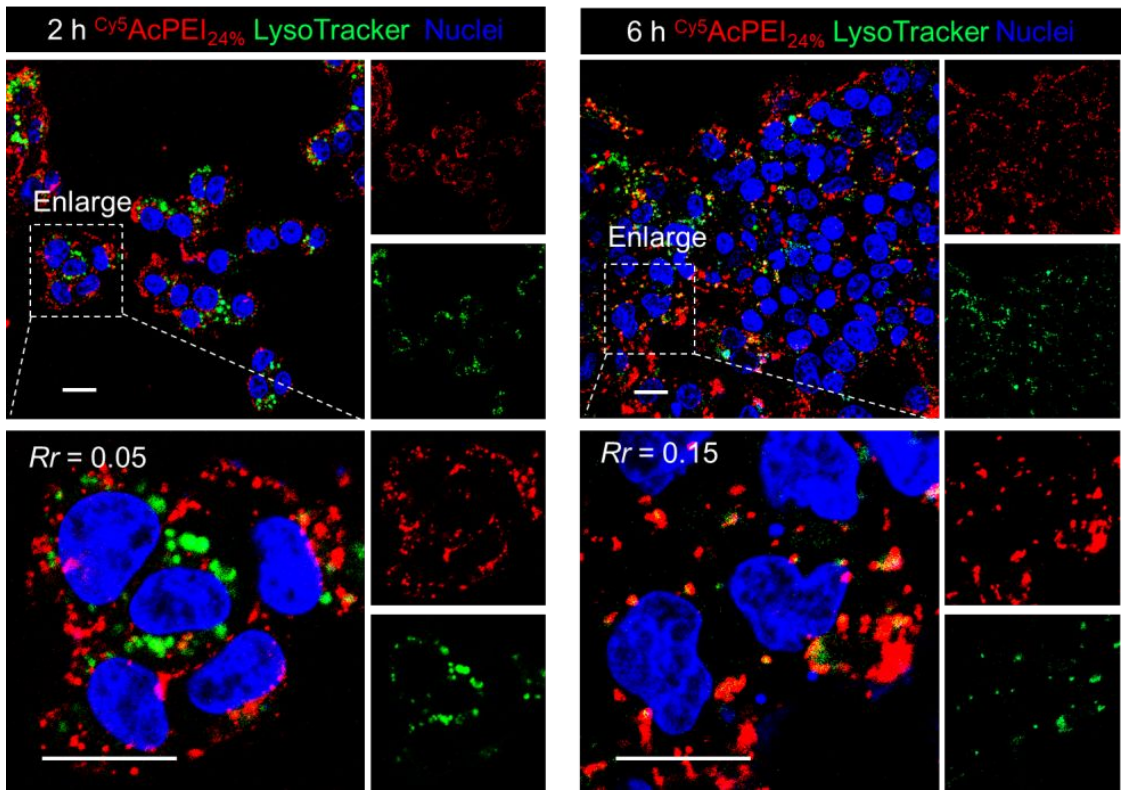

Figure S6. Colocalization of ${ }^{\mathrm{Cy} 5} \mathrm{AcPEI}_{24 \%}$ (red) with lysosomes (green) observed by CLSM. HepG2 cells are cultured with ${ }^{\mathrm{Cy} 5} \mathrm{AcPEI}_{24 \%}\left(\mathrm{Cy} 5\right.$-equiv. $\left.0.2 \mu \mathrm{g} \mathrm{mL}{ }^{-1}\right)$ for $2 \mathrm{~h}$ or $6 \mathrm{~h}$; Scale bars, $20 \mu \mathrm{m}$. The Pearson's correlation $(R r)$, a measure of the significance of the correlation between red and green fluorescence, is calculated by Image-Pro Plus software.
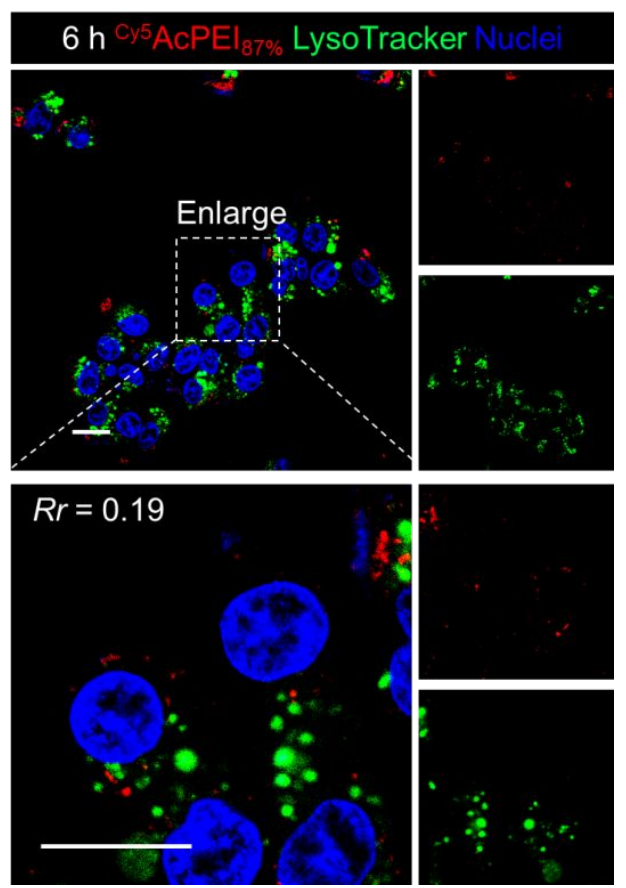

Figure S7. Colocalization of ${ }^{\mathrm{Cy} 5} \mathrm{AcPEI}_{\mathbf{8 7} \%}$ (red) with lysosomes (green) observed by CLSM. HepG2 cells are cultured with ${ }^{\mathrm{Cy} 5} \mathrm{AcPEI}_{24 \%}$ (Cy5-equiv. $0.2 \mu \mathrm{g} \mathrm{mL} \mathrm{mL}^{-1}$ ) for $6 \mathrm{~h}$; Scale bars, 20 $\mu \mathrm{m}$. The Pearson's correlation $(R r)$, a measure of the significance of the correlation between red and green fluorescence, is calculated by Image-Pro Plus software. 
A

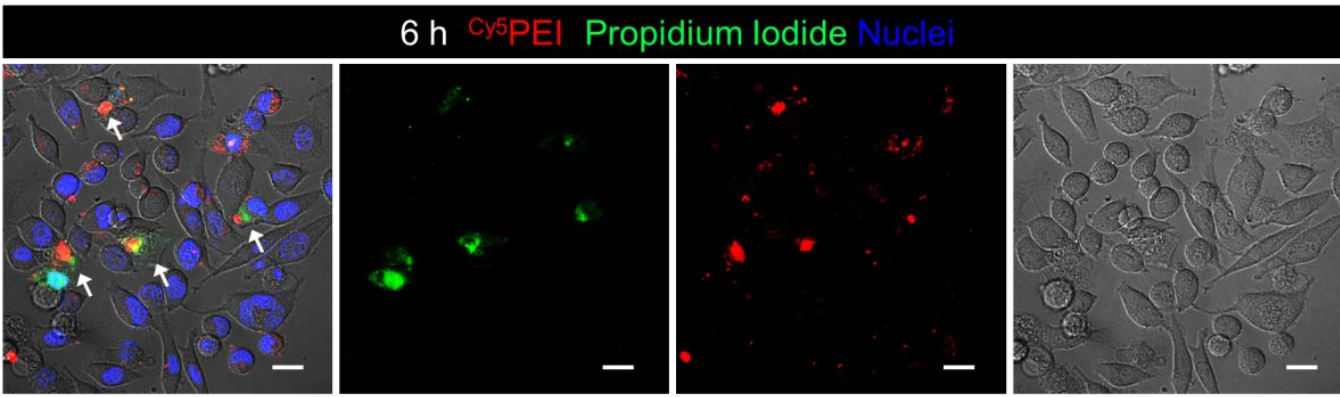

B

\section{$6 \mathrm{~h}{ }^{\mathrm{Cy}} \mathrm{ACPEI}_{2,0}$. Propidium lodide}
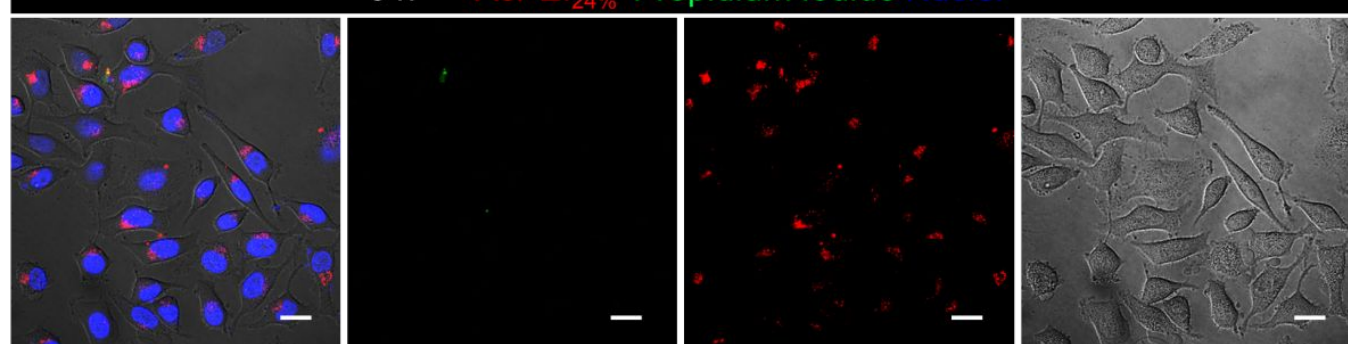

Figure S8. Cytotoxicity of ${ }^{\mathrm{Cy} 5} \mathrm{PEI}$ or ${ }^{\mathrm{Cy} 5} \mathrm{AcPEI}_{24 \%}$ (red) against HepG2 cells determined by propidium iodide staining (green). (A-B) HepG2 cells are cultured with ${ }^{\mathrm{C}} 5 \mathrm{PEI}$ (A) or ${ }^{\mathrm{Cy} 5} \mathrm{AcPEI}_{24 \%}$ (B) at Cy5-equiv. dose of $0.2 \mu \mathrm{g} \mathrm{mL}^{-1}$ for $6 \mathrm{~h}$; The apoptotic cells are stained with propidium iodide $(1.0 \mu \mathrm{M})$ for 10 min and imaged via CLSM. Scale bars, $20 \mu \mathrm{m}$.

\section{Without wash: 2 h ${ }^{C y 5}$ PEI FITCW GA}

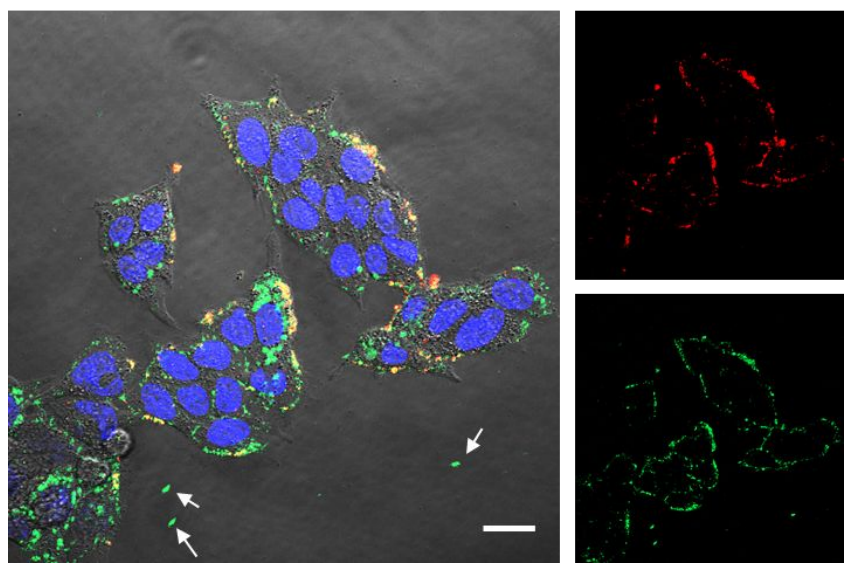

Figure S9. Imaging the budding of extracellular vesicles (EVs) in Cy5PEI treated HepG2 cells. HepG2 cytomembrane is stained with FITCWGA then imaged immediately after adding ${ }^{\mathrm{Cy}} 5 \mathrm{PEI}$ (Cy5-equiv $0.2 \mu \mathrm{g} \mathrm{mL}^{-1}$ ) via the time-lapse-acquisition mode. The representative image is taken at $2 \mathrm{~h}$-post-incubation and the EVs' signals (green) are indicated by arrows; Scale bars, $50 \mu \mathrm{m}$. 